\title{
The Use of Tangible User Interface in Interactive System to Learn about Countries
}

\author{
https://doi.org/10.3991/ijet.v14.i04.9341
}

\author{
Wafa Almukadi $\left.{ }^{\bowtie}\right)$, Nahla Aljojo, Asmaa Munshi \\ Jeddah University, Mekkah, Saudi Arabia \\ walmukadi@kau.edu.sa
}

\begin{abstract}
Tangible User Interface (TUI) is an interface that allows user to interact with digital information through physical environment. We have developed an interactive system serves the educational field within the geographical domain. The system allows children to discover and learn about countries from different continents using tangible objects. In our project we selected so far six countries that represent six continents in the world. The selected countries are: Saudi Arabia, Egypt, United States of America, France, Brazil, and Australia. With the system, children are required to manipulate tangible objects. Their task is to select a landmark from a country and placing it on the table top. The system will recognize the object and provides users with feedback. The system involves the recognition of six elements for each country: (capital, flag, climate, currency, population and industries). This application has been evaluated in a field study with children 9-11 years of age. The initial results are promising and show that such an interactive system can support interaction and collaboration among young children, as well as enriches the learning process and makes it more enjoyable.
\end{abstract}

Keywords-Tangible User Interface (TUI), Learning, Education, Geographic, Countries, edutainment, collaboration, Fun.

\section{$1 \quad$ Introduction}

New interactive systems such as mobile device, tablet, games and simulations, Tangible User Interface (TUI) have spread dramatically in the educational field. These systems allow interaction between user and digital information through physical objects. Using these systems for learning purpose can create an interactive environment that support edutainment for both students and teachers. Specifically, TUI support collaborative activities and promoted social learning process [4]. We propose in this paper to increase another technology to this range of products: Discover Countries interactive system (Figure 1).

We decided to use TUI concept that that allows users to interact with digital information through physical environment [8]. The proposed system are mainly based on reacTIVision platform which is a computer vision framework for the fast tracking of fiducial markers attached onto physical objects [9]. The system detects objects 
equipped with fiducial markers when they are placed on the table. Each object has a unique fiducial marker that allows the system to retrieve and display the data for each object. The system has six different objects represents the land mark for each country. Kaaba for Kingdom of Saudi Arabia, Amazon Theater for Brazil, Pyramid for Egypt, Opera house for Australia, Eiffel tower for France, and Statue of Liberty for United State for America (Figure 2). By placing an object on the table, basic information of the country will display on the computer screen with oral and visual feedback. Basic information include: climate, industries, population, flag, capital and currency).

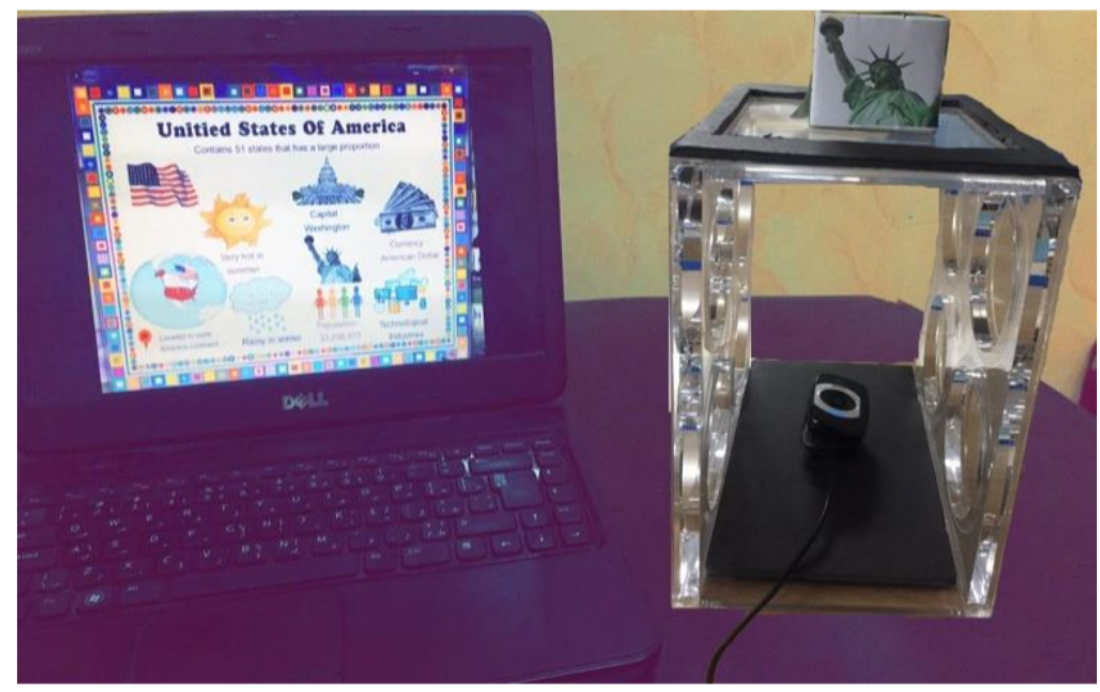

Fig. 1. Discover Countries interactive system. Using Statue of Liberty object to display information about USA

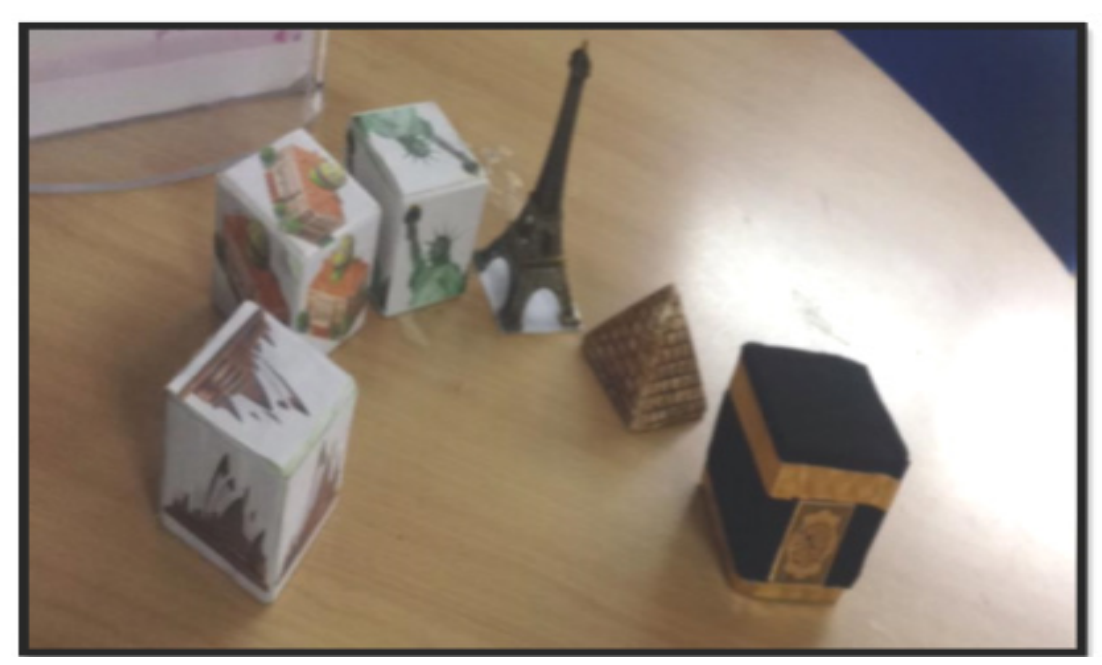

Fig. 2. The six objects (land marks) of the system 
In recent years there has been an increasing development of interactive technology that promotes learning and play $[13,14,7,6,18,1,10,2,11]$. Discover Countries interactive system used in a school class with children to learn and recognize different countries and landmark from different continents. An empirical experiment was performed with 50 children to evaluate the affect of TUIs in children's learning environment. In this paper, we plan to propose design and architecture for the interactive table, as w. In addition, we will share the results of the experiment.

\subsection{Learning with tangible technology}

TUI attempt to take everyday objects and invest them with computation instead of sitting in front of a screen using a keyboard and a mouse to point and click on digital data.[5] shows that children are more productive when they cooperate with peers in a group of children and more able to do tasks in efficiently way. [12] Illustrates that learning with TUI supports conceptual metaphors and enhance learning for mathematics in young children. Scientists [3] suggest that TUI is a good solution for providing innovative ways for children to play and learn, through novel forms of interacting and discovering. Antle, propose a Tangible Learning Design Framework [15] argues that TUIs present unique opportunities to support learning interactions by reducing cognitive load and mappings between physical and digital objects.

Many studies $[15,20,17,16]$ provides evidence of TUI benefits in learning with children in different domains, such as color, mathematics, chemistry, numbers, shapes, programming language and much more. However, little empirical work exists that provides evidence for enhanced learning geographic domain, especially in learning about countries, continents, and their famous landmark. Discover Counties interactive system develop to enrich the learning process and makes it more enjoyable within the geographical domain. It design by providing the users an over control of the system in a digital space, while matching between the real world and the digital one.

\section{The Tabletop as Learning Interface}

Discover Countries interactive system is a table-top, tangible user interface with which to interact with physical objects and present information. We are developing a system that includes software that enables users to transform tabletop physical objects into interactive tokens. Our setup is adopted from [2] which consist of a transparent box that has useful tabletop surface, webcam, and everyday objects that are tagged with fiducial markers. The fiducial markers attached at the bottom of the objects can be recognize by a webcam, and manipulating the objects creates and alters information and feedback that are displayed on screen. 


\subsection{How does it work?}

The bottom of each landmark is attached with a fiducial marker specially designed to be identified by the reacTIVision platform [9]. The web camera placed below the table captures the image of the fiducial markers in real time. The reacTIVision recognizes the ID of each identified marker while this information is interpreted by the TUIO protocol. TUIO protocol is adopted for encoding the state of tangible objects from our interactive tabletop, and then transfer it into our system's software. The system software developed by Processing 1programming sketchbook (Figure 3).

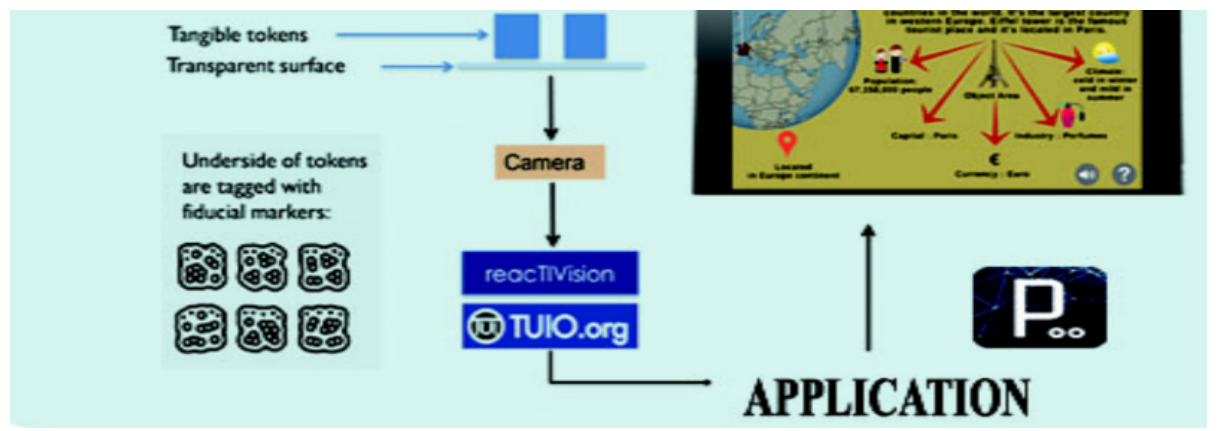

Fig. 3. A schema clarify how does the system work

\section{Experimental Design and Evaluation}

We conducted a user study in a private school located at Jeddah, Saudi Arabia. 50 students participated in the testing process. The students are in the age group of 9-11 (all are girls). The students are vary between third, fourth and fifth grades.

The prime goal of this study is to comprehend that using TUI improve children learning. In particular we are interested in:

- Does Discover Countries interactive system enhance children collaboration?

- Does Discover Countries interactive system support playfulness while learning?

- Students achievements "grades" after using the system

- The time taken to answer the questions?

\subsection{Experiment procedure}

Sessions took place in children classroom, while noise levels and distraction were on control. There were five children per each session. Sessions lasted between twelve and twenty minutes. It was then explained in general terms that the goal of the study was to find out what help children learn about countries. At first, all groups asked to answer questions about some countries information such as: capital, flag, currency,

\footnotetext{
${ }^{1}$ Processing (2014) Processing Software and Language. Available at: https://processing.org/
} 
weather, and landmark. We called this session DegreePre. Students answer the questions using paper and pencils. After that, each group asked to play with the system.

The researchers sit the landmark objects on a table and asked the students to place the landmark on the interactive system table. While the land mark on top of our system's table, the information of the country is displayed on the laptop's screen, see Figure 4 . Each group should try all the six land marks.
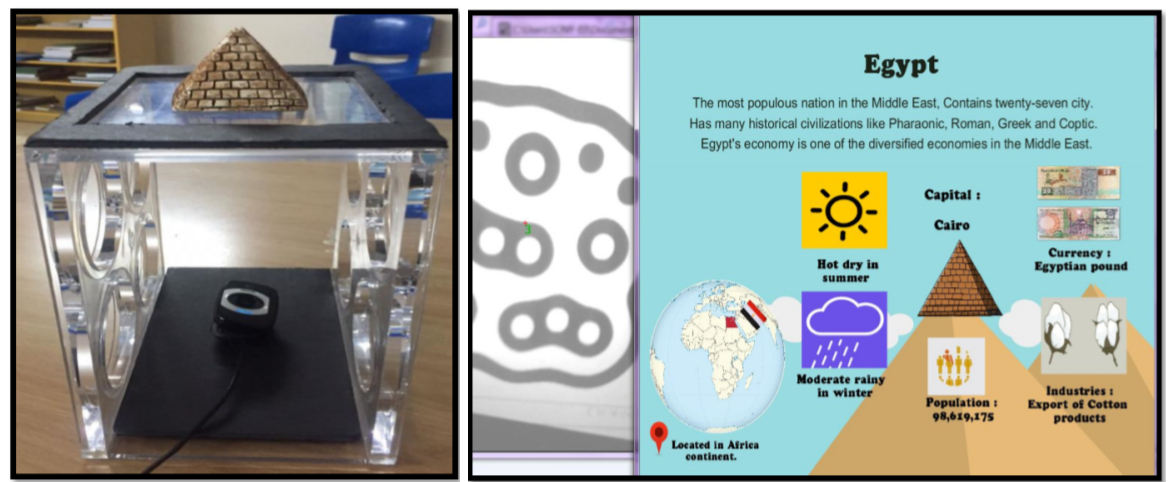

Fig. 4. On the right placing pyramid object on the table. On the left information about Egypt is displayed on the screen.

Later than, all groups were asked to answer questions about some countries information such as: capital, flag, currency, weather, and landmark. It was different questions than the one in the Degree Pre-session. We called this session Degree Post.

\subsection{Test hypotheses}

The 'null hypothesis' might be:

- H0: There is no difference in mean pre- and post-grades

An alternative hypothesis' might be:

- H1: There is a difference in mean pre- and post-marks. See Figure 5

The relevant results for the paired t-test:

We observe the $\mathrm{t}$ statistic, $\mathrm{t}=-5.081$, and $\mathrm{p}=0.00$.

The null hypothesis is rejected, since $\mathrm{p}<0.05$ (in fact $\mathrm{p}=0.00$ ).

Linear Regression Analysis The regression analyses for the post degree as independent factor, with time, collaboration and age as dependent factors. See Figure 6

There are two dependent factors that affect the degree "grade", which are collaboration and age. The collaboration $\mathrm{t}=2.134$, and $\mathrm{p}=0.038$, and age $\mathrm{t}=6.288$, and $\mathrm{p}=$ 0.000 . The null hypothesis is rejected, since $\mathrm{p}<0.05$ (in fact collaboration $\mathrm{p}=0.038$ and age $\mathrm{p}=.000$ ). 
In addition, after the students finished using our TUI system we asked them to fill the evaluation form. The purpose of the evaluation form is to test the usability factors of the interactive system as well as to ensure that the system is error free. See Table 1.

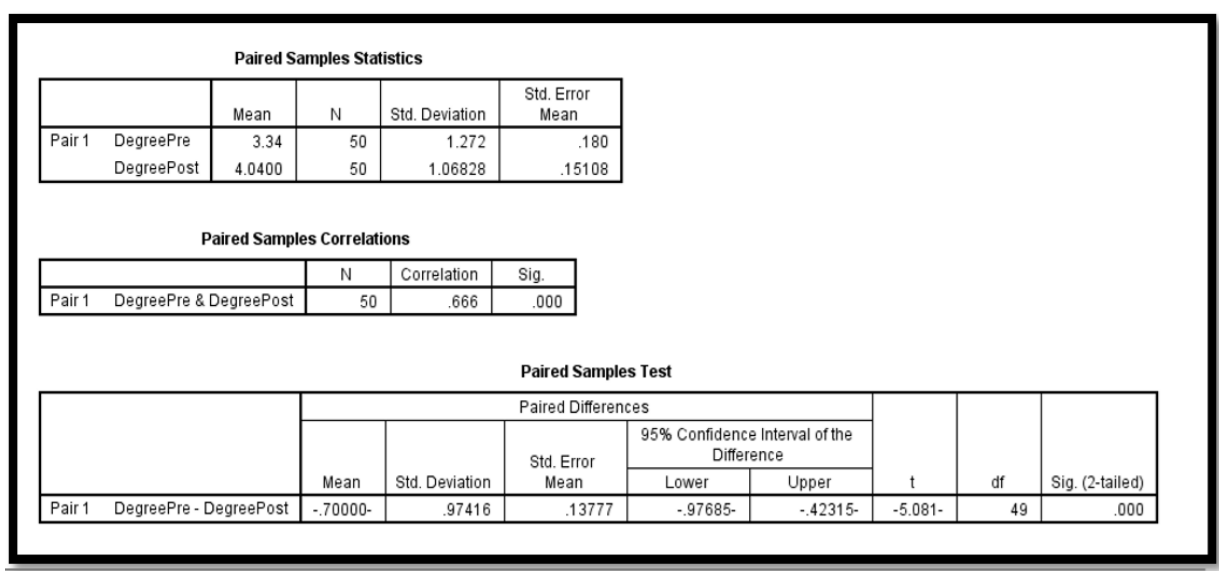

Fig. 5. Paired T-Test

\begin{tabular}{|c|c|c|c|c|c|c|}
\hline \multicolumn{7}{|c|}{ Coefficients $^{a}$} \\
\hline \multirow[b]{2}{*}{ Model } & & \multicolumn{2}{|c|}{ Unstandardized Coefficients } & \multirow{2}{*}{$\begin{array}{c}\text { Standardized } \\
\text { Coefficients } \\
\text { Beta }\end{array}$} & \multirow[b]{2}{*}{$\mathrm{t}$} & \multirow[b]{2}{*}{ Sig. } \\
\hline & & B & Std. Error & & & \\
\hline \multirow[t]{4}{*}{1} & (Constant) & -7.055 & 1.895 & & -3.722 & .001 \\
\hline & TimePost & .210 & .211 & .125 & .997 & .324 \\
\hline & CollaborationPost & .492 & .231 & .213 & 2.134 & .038 \\
\hline & Age & .927 & .147 & .784 & 6.288 & .000 \\
\hline
\end{tabular}

a. Dependent Variable: DegreePost

Fig. 6. Linear regression 
Table 1. The evaluation and assessment form of Discover Countries Interactive System

\begin{tabular}{|c|c|c|c|}
\hline Question & Answer & Total & Average \\
\hline \multirow{3}{*}{$\begin{array}{l}\text { Does the overall system is } \\
\text { attractive? }\end{array}$} & Yes & 50 & $100 \%$ \\
\hline & No & 0 & $0 \%$ \\
\hline & Somehow & 0 & $0 \%$ \\
\hline \multirow{3}{*}{$\begin{array}{l}\text { Does the system have a good } \\
\text { balance of text? }\end{array}$} & Yes & 45 & $90 \%$ \\
\hline & No & 0 & $0 \%$ \\
\hline & Somehow & 5 & $10 \%$ \\
\hline \multirow{3}{*}{$\begin{array}{l}\text { The information is easy to } \\
\text { read? }\end{array}$} & Yes & 43 & $86 \%$ \\
\hline & No & 2 & $4 \%$ \\
\hline & Somehow & 5 & $10 \%$ \\
\hline \multirow[t]{3}{*}{ Do you like to use again? } & Yes & 42 & $84 \%$ \\
\hline & No & 2 & $4 \%$ \\
\hline & Somehow & 6 & $12 \%$ \\
\hline \multirow[t]{3}{*}{ Do you like the system? } & Yes & 47 & $94 \%$ \\
\hline & No & 0 & $0 \%$ \\
\hline & Somehow & 3 & $6 \%$ \\
\hline \multirow{3}{*}{$\begin{array}{l}\text { Does the colors used in the } \\
\text { system are attractive? }\end{array}$} & Yes & 47 & $94 \%$ \\
\hline & No & 0 & $0 \%$ \\
\hline & Somehow & 3 & $6 \%$ \\
\hline
\end{tabular}

The results show high acceptance of the system from the students with good percentage of usability factors.

\section{Conclusion}

Many researchers have suggested that tangible user interface (TUI) have significant impacts on learning. It promotes collaboration, exploratory and expressive activities, offer learning of abstract concepts through concrete representations and allow embodied interaction. However, little empirical work exists that provides evidence for enhanced learning in geographic domain, specifically for learning about countries and its basic information by young children (9-11 years). Our study has shown that children can identify more county using landmark objects. At the same time, children were able to clarify country's flag, capital, and currency more easily using Discover Country interactive system than using a book. We can say that using TUI with children improve their learning about different countries. As well as, it improves their collaboration and raises their motivation to learn more about countries. 


\section{Acknowledgement}

We thank all schools, teachers, children, and participants in this study. Thanks to Afa Alamri, Asmaa Althaqafi, Ebtisam Alshehry, Haneen Albarqi, Ebtihal Alqarni, and Koloud Aljehani for the help in implementation and testing session.

\section{References}

[1] Almgren, J., Carlsson, R., Erkkonen, H., Fredriksson, J., Moller, S., Rydgard, H., Osterberg, M. and Fjeld, M., 2005, November. Tangible user interface for chemistry education: Visualization, portability, and database. In SIGRAD 2005 The Annual SIGRAD Conference Special Theme-Mobile Graphics (No. 016, pp. 19-24). Linköping University Electronic Press.

[2] Almukadi, W., \& Stephane, A. L. (2015, November). BlackBlocks: tangible interactive system for children to learn 3-letter words and basic math. In Proceedings of the 2015 International Conference on Interactive Tabletops \& Surfaces(pp. 421-424). ACM.

[3] Antle, A. \& Wise, A. (2013). Getting down to details: Using learning theory to inform tangibles research and design for children, Interacting with Computers, 25, 1 (2013), 1-20. http://doi:10.1093/iwc/iws007.

[4] Bertrand Schneider, Kshitij Sharma, Sebastien Cuendet, Guillaume Zufferey, Pierre Dillenbourg, and Roy Pea. 2016. Using Mobile Eye-Trackers to Unpack the Perceptual Benefits of a Tangible User Interface for Collaborative Learning. ACM Transactions on Computer-Human Interaction 23, 6 (2016), 1-23.

[5] Chaliampalias, R., Chronaki, A., \& Kameas, A. Tangible User Interfaces in early year mathematical education: An experimental study.

[6] Druin, A., L. Hanna, et al. (1999). The Design of Children's Technology, Moran Kaufmann Publishers, Inc

[7] Hedley, N. R., Billinghurst, M., Postner, L., May, R., \& Kato, H. (2002). Explorations in the use of augmented reality for geographic visualization. PRESENCE: Teleoperators and virtual environments, 11(2), 119133

[8] Ishii, H. \& Ullmer, B. (1997). Tangible Bits: Towards Seamless Interfaces between People, Bits, and Atoms Tangible bits: towards seamless interfaces between people, bits and atoms. In Proceedings of the SIGCHI Conference on Human Factors in Computing Systems (Atlanta, Georgia, United States, March 22 - 27). S. Pemberton, Ed. CHI '97. ACM, New York, NY, 234-241. http://doi.acm.org/10.1145/258549.258715.

[9] Kaltenbrunner M. \& Bencina R., "reacTIVision: a computer-vision framework for table based tangible interaction", TEI '07: Proceedings of the 1st international conference on Tangible and embedded interaction, 2007.

[10] Newton-Dunn, H., Nakano, H. and Gibson, J. (2003). Block Jam: A Tangible Interface for Interactive Music. Journal of New Music Research, 32(4), pp.383393.

[11] O'Malley, C., \& Fraser, D. S. (2004). Literature review in learning with tangible technologies.

[12] Price, S., Rogers, Y., Scaife, M., Stanton, D., \& Neale, H. (2003). Using 'tangibles' to promote novel forms of playful learning, Interacting with Computers, 15(2), 169-185.D.L.

[13] R.J. Jacob, H. Ishii, G. Pangaro, and J. Patten, "A Tangible Interface for Organizing Information Using a Grid," Proc. SIGCHI Conf. Human Factors in Computing Systems (CHI '02), pp. 339-346, 2002. 
[14] Schneider, B., Wallace, J., Blikstein, P. and Pea, R. (2013). Preparing for Future Learning with a Tangible User Interface: The Case of Neuroscience. IEEE Transactions on Learning Technologies, 6(2), pp.117-129.

[15] Schneider, B., Wallace, J., Blikstein, P. and Pea, R. (2013). Preparing for Future Learning with a Tangible User Interface: The Case of Neuroscience. IEEE Transactions on Learning Technologies, 6(2), pp.117-129

[16] Sylla, C., Branco, P., Coutinho, C., Coquet, E. and Skaroupka, D., 2011, May. TOK: a tangible interface for storytelling. In CHI'11 Extended Abstracts on Human Factors in Computing Systems (pp. 1363-1368). ACM.

[17] Tateosian, L., Mitasova, H., Harmon, B., Fogleman, B., Weaver, K., \& Harmon, R. (2010). TanGeoMS: Tangible geospatial modeling system. IEEE transactions on visualization and computer graphics, 16(6), 1605-1612.

[18] Terrenghi, L., Kranz, M., Holleis, P., \& Schmidt, A. (2006). A cube to learn: a tangible user interface for the design of a learning appliance. Personal and Ubiquitous Computing, 10(2-3), 153-158

[19] Xu, D., 2005. Tangible user interface for children-an overview. In Proc. of the UCLAN Department of Computing Conference.

[20] Zaman, B., VandenAbeele, V., Markopoulos, P. and Marshall, P. (2011). Editorial: the evolving field of tangible interaction for children: the challenge of empirical validation. Personal and Ubiquitous Computing, 16(4), pp.367-378

\section{Authors}

Dr. Wafa Almukadi is an Asst Professor, Information system department at the Jeddah university with 20 years of research experience in the fields of 'Child centric learning like - Pleasurable learning and Enhancing and Facilitating', Blackholes etc...

Dr. Nahla Aljojo has a doctorate in E-Learning and Learning Styles from Portsmooth Uniaversity, UK in 2012 and renders services as Asst Professor in IS department of King Abdul-Aziz University. Has submitted around 21 papers in 20 years. naljojo@kau.edu.sa

Dr. Asmaa Munshi is an Asst. Professor \& Supervisor of Computers, University of Jeddha, SA https://scholar.google.com/citations?user=fdEP coAAAAJ\&hl=en

Article submitted 04 August 2018. Resubmitted 14 October 2018. Final acceptance 17 January 2019. Final version published as submitted by the authors. 